\title{
Suicide in rural Punjab, India: implications for ensuring farmer rights
}

Faten Taki ${ }^{1}$ (ㅇ, Melanie Witte ${ }^{2}{ }^{a}$, Inderjit Singh Jaijee ${ }^{3}$, Sonal Jessel ${ }^{4}$, Elizabeth Mauer ${ }^{5}$, Jacob Lurie ${ }^{1}$, Gunisha Kaur ${ }^{1}$ (C)

${ }^{1}$ Department of Anesthesiology, Weill Cornell Medicine, NYC, NY, USA, 2 Department of Anesthesiology, University of Texas Medical Branch at Galveston, Galveston, TX, USA, ${ }^{3}$ Baba Nanak Education Society, India, ${ }^{4}$ WE ACT for Environmental Justice, NYC, USA, ${ }^{5}$ Department of Population Health Sciences, Weill Cornell Medicine, NYC, NY, USA

Keywords: economic burden, india, rural punjab, debt, farmer suicide

https://doi.org/10.29392/001c.22236

\section{Journal of Global Health Reports}

Vol. 5, 2021

\section{Background}

Suicide is prevalent among farmers worldwide, and may be influenced by policies and agricultural initiatives that affect the socioeconomic insecurity. The objective of this study was to investigate the association between economic burden and suicides in rural areas of Punjab, India.

\section{Methods}

Suicide data were collected using household verbal autopsy surveys by the Baba Nanak Education Society, a local non-governmental organization, from 1980 to 2016. Data from five districts were analyzed: Mansa, Sangrur, Fatehabad, Jind, Patiala. Demographic data included the date at which death by suicide occurred, age, occupation, land holding, information on the debt, and the mode of suicide, for 2,473 suicides.

\section{Results}

Suicides were more prevalent among agricultural workers, which include agricultural laborers and agriculturalists (i.e. individuals involved in the business of owning agricultural land and cultivation). Agricultural workers were significantly more likely to commit suicide by poisoning, while those from other occupations preferred different means. The median age was lower in agricultural workers relative to other occupations. The frequency of suicides among agricultural workers significantly increased from 1980 to 2016. This increase was strongly correlated with the total annual debt and land holding.

\section{Conclusions}

Results from this study suggest that increasing debt and land holding may significantly predispose young and middle-aged farmers to death by suicide. Policies are needed to limit the availability of hazardous chemicals that can be used as poison and to protect the economic security of farmers in Punjab and other parts of the world.

Suicide, defined as a self-directed, fatal act with intent to die as a result of that same act, is a public health challenge worldwide. ${ }^{1}$ It is a complex phenomenon influenced by many factors such as neurobiology, stressful events, socioeconomic and cultural environment. ${ }^{2}$ Death by suicide is overrepresented in farmers worldwide, ${ }^{3-6}$ especially in regions that are economically dependent on the agricultural output. The socioeconomic stress may play an even greater role than mental health disorders in driving high suicide rates among farmers in India. ${ }^{7}$ Farmer suicides have been considered as 'political acts', used by the desperate agricultural workers to protest against the dire conditions that they experience. ${ }^{8}$ This is evident from the recent countrywide 'winter of content' protests against government policies that left farmers feeling particularly vulnerable. ${ }^{9}$

Farming, as a profession, is subject to many uncertainties and risks, which are mostly arising from economic insecurity. The most important among them are unpredictable climate, the risk of crop failure, price volatility of agricultural goods due to increased access to foreign markets, and unintended consequences of the Green Revolution. The latter include higher costs of production, manipulation by middlemen, logistical barriers, insufficient support systems, expensive loans with high interest rates, corporate 
control, aggressive loan recovery programs, among others, all contribute to the escalation of debt traps, especially among marginal farmers. ${ }^{7}$ These factors resulted in widening disparities in land distribution and higher rates of unemployment. ${ }^{10}$

In India, most agricultural suicides were reported in the states of Andhra Pradesh, Karnataka, Kerala, Maharashtra, and Punjab between $1998-2006 .{ }^{8}$ Despite improvements in the number of suicides in industrial states like Tamil Nadu (population of 7 million) which recorded zero suicides from 2010-2018, agrarian states like Maharashtra (population of 11 million) and Punjab (population of 2 million) recorded 6833 and 649 suicides, respectively in the same period. ${ }^{11}$ The prevalence of suicide from 2008-2018 in Punjab was 1190 out of 279,233 medically certified deaths in the population. ${ }^{11}$ However, suicide events were under-reported since suicide was considered illegal until $2014 .^{12}$ In addition, most of these reports are not associated with information on the individual's economic status, which makes correlational analyses unreliable.

There is an increasing trend in the number of recorded suicide cases in Punjab during the past 30 years. Despite the rise of several initiatives, such as agricultural debt waiver and relief as well as Kisan credit card loan ${ }^{13}$ and spiritual and rehabilitation programs, ${ }^{8}$ to address farmers' suicide, there is a systemic failure to offset the root causes. Therefore, the aim of this study was to uncover the causes of suicide, by providing improved evidence on the importance of ensuring farmers' rights by implementing policies that protect their economic security and make them less vulnerable to debt spirals.

\section{METHODS}

\section{STUDY DESIGN}

Data were reviewed from the household verbal autopsy surveys from 102 villages between 1980 and 2016 by the Baba Nanak Education Society (BNES), a local non-governmental organization based in Punjab, India. Detailed surveys on factors related to the death of an individual were conducted by BNES staff at the homes of each family where a suicide had recently occurred. These data were confirmed by signed affidavits by the local village council. Seven districts (Mansa, Sangrur, Samana, Fatehabad, Jind, Sanrur, Patiala) were included in the data collection, spanning across the three districts in Punjab that have greater agricultural focus (Sangrur, Mansa, Patiala) and one district in the neighboring state of Haryana (Jind). Response rate to household surveys was nearly $100 \%$, with confirmation by Panchayat (village council) affidavit in $93 \%$ of cases. This study does not constitute human subjects research as all subjects are deceased. Institutional Review Board (IRB) approval was obtained from Weill Cornell Medicine to use protected health information (PHI) for descendants of this study for research purposes.

\section{DATA SOURCES}

Data were obtained from BNES in 2016. Data cleaning and analysis took place from August 2017 to November 2020. Demographic data, including the date of the suicide, age, occupation, landholding, available debt information, and the mode of suicide were recorded.

\section{STATISTICAL ANALYSES}

Suicides with at least one missing data point were excluded. The location of each individual's village was plotted onto a map based on village coordinates from official government census data, with suicides subsequently grouped according to Tehsil (sub-district) and district. This was done using the R packages: cowplot, googleway, ggplot2, ggrepel, ggspatial, libwgeom, sf, rnaturalearth, rnaturalearthdata. Bar plot was used to show the distribution of suicides across the different occupations. The dataset was then split by occupation. Agriculturalists (i.e. individuals involved in the business of owning agricultural land and cultivation) and agricultural laborers were grouped under 'agriculture' and were referred to as 'agricultural workers' in the text. All other occupations (tailor, shop keeper, government service, housewife, shop laborer, watchman, driver, barber, car mechanic, carpenter, tea seller, trader, truck driver, and service) were denoted as 'other' and were referred to as 'other workers' in the text. The frequencies of suicides and modes of suicide, sum of debts, and the sum of land holding for the total suicides per year were computed and were merged into one dataset. Boxplots were used to show the distribution of suicide age per year. The median age per year was computed and was used to analyze statistical significance between the two categories. Statistical significance was set at the alpha level of 0.05 for linear regression models. Adjusted odds ratio were computed to study the relationships between suicide frequency and total debt or land holding. Analyses were performed using $\mathrm{R}$ software, version 4.0.3 (Vienna, Austria).

\section{RESULTS}

\section{OVERVIEW OF THE DEMOGRAPHICS}

There were 2,489 recorded suicides during the study period, with complete data available for 2,473. 58.39\% of the recorded suicides were among agriculturalists and $40.72 \%$ were among agricultural laborers. The remaining recorded suicides were recorded for other occupations (barber, car mechanic, carpenter, driver, government service, house wife, service, shop laborer, shopkeeper, tailor, tea seller, trader, truck driver, watchman) (Figure 1, panel A). Most of the cases were in Sangrur (2228/2473) and Mansa (223/ 2473) districts (Figure 1, panel A).

Agricultural workers (i.e. agriculturalists and agricultural laborers) most commonly committed suicide by poisoning $(\mathrm{t}(60)=5.21, P=2.480 e-6)$, a trend that increased from 1980 to $2016(\mathrm{t}(60)=2.80, P=0.007)$ (Figure 1 , panel $\mathrm{B})$.

The average median age at the time of suicide was 33 and 39 years for agricultural and other workers, respectively. Agricultural workers who died by suicide were significantly younger than other workers $(\mathrm{t}(42)=3.27, P=0.002)$. The highest median age for agricultural workers was 45 years, while that of other workers was 55 years (Figure 1, panel $\mathrm{C}$ and Table 1). 
THE ASSOCIATION BETWEEN SUICIDE FREQUENCY, DEBT, AND LAND HOLDING

The frequency of suicide cases and the sum of debt per year increased throughout the years among agricultural workers $(\mathrm{t}(31)=3.24, P=0.003, \mathrm{t}(31)=4.58, P=7.170 e-5$, respectively) (Figure 2, panels A and B). Land holding did not change dramatically throughout the years (Figure 2, panel C).

Not surprisingly, debt increased the suicide risk throughout the years regardless of occupation (agriculture: $\mathrm{t}(31)=9.36, \quad P=1.56 e-10$, Other occupations: $\mathrm{t}(31)=2.97$, $P=0.014)$. However, the relationship was stronger in agriculture (odds ratio, OR=2.94, 95\% confidence interval, $\mathrm{CI}=2.33-3.72)$ relative to other occupations $(\mathrm{OR}=1.28,95 \%$ $\mathrm{CI}=1.06-1.54$ ) (Figure 3, panel A). Land holding was also correlated with suicide frequency. This relationship was only evident in agriculture $(\mathrm{t}(31)=7.08, P=5.9 e-8 ; \mathrm{OR}=2.77$, 95\% $\mathrm{CI}=2.07-3.72)$, but not in other occupations $(\mathrm{t}(10)=0.31$, $P=0.760 ; \mathrm{OR}=1.08,95 \% \mathrm{CI}=0.63-1.84$ ) (igure 3, panel B).

\section{DISCUSSION}

This study confirmed that debt and land holding are precipitating factors for suicide among farmers in rural Punjab, India. Farmer suicide is a universal phenomenon. ${ }^{14-16}$ In India, it has been estimated that one suicide among farmers occurs every 30 minutes. ${ }^{17}$ While each suicide is a tragedy caused by a unique set of circumstances, there are likely occupational risks and hazards that predispose numbers of farmers in despair to take their own lives. It is therefore important to address the root causes, in order to potentially reverse the pattern of recorded suicides.

This study found that farming shortened the lifespan of workers (median max $=45$ years) by up to 10 years relative to other occupations (median $_{\text {max }}=55$ years) (Figure 1 , panel $\mathrm{C}$ and Table 1). This trend was different in other reports in India where the highest number of suicides was among 15-29 year olds ${ }^{18}$ and in the US where the number of suicides remained high for $>75$ year olds from 1999-1994, while the highest increase was among the middle-aged group (45-64). ${ }^{19}$ Farmers were significantly more likely to die by suicide as a result of poison. This is consistent with previous reports, suggesting that the majority of death by suicide among farmers in India was by ingestion of insecticides $^{20}$ and pesticides, ${ }^{21}$ which were available in farms or the households. The number of farmer suicides increased in these rural regions despite national bans for pesticide use in India, ${ }^{22}$ suggesting that pesticide regulation may not be efficient in rural areas and fails to address the root causes of farmer suicides. In comparison, 590 farmers in three southeastern states in the US were more likely to use firearms as a means for death by suicide during the period of 1990 to 1998. ${ }^{15}$ Firearms were also the most prevalent method for death by suicide among 662 farmers in England during of the period of 1979 to $1994 .^{23}$ This difference may suggest region-specific conditions and cultures that influence the ability to access or use certain methods. The number of suicides, debt, and land holding did not decline over the years despite initiatives aimed at mitigating the economic burden for farmers. Both debt and land holding increased the risk for suicide among farmers. These results confirm previous

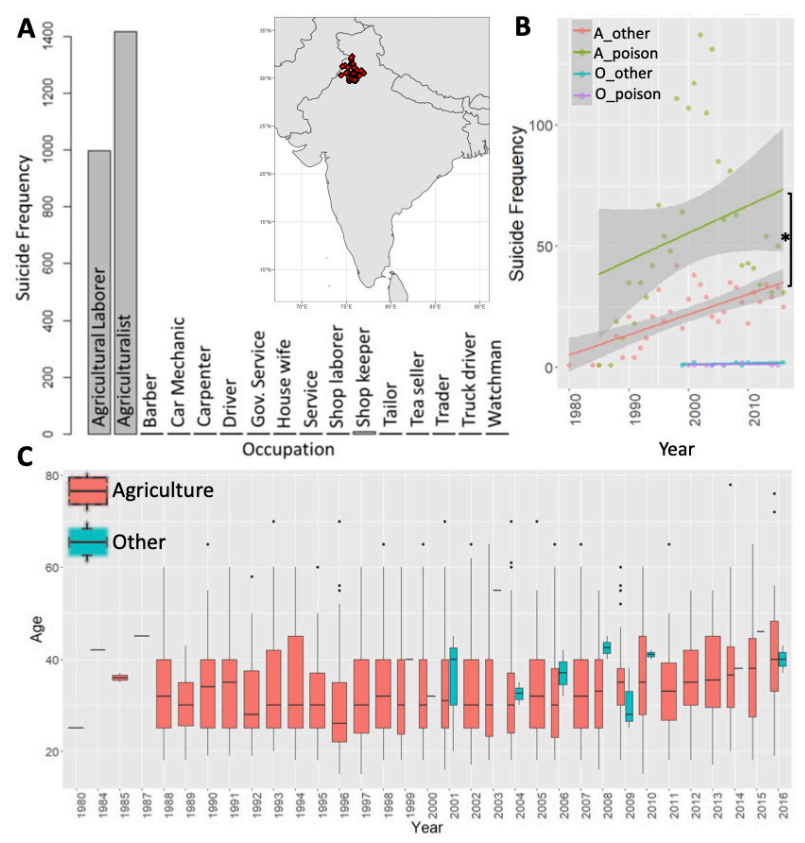

Figure 1. Demographics of death by suicide events in rural India.

(A) The distribution of suicide events by occupation and geography. Data was collected by Baba Nanak Education Society (BNES), from 1980-2016 in rural India. (B) The frequency of suicide by poison increased throughout the years and was higher than other modes among agricultural workers. This was not evident in suicide cases for other occupations. Linear regression model. (Agriculture): Year: $\mathrm{t}(60)=2.80, * P=0.007$. Mode of suicide: $\mathrm{t}(60)=5.21, P=2.48 \mathrm{e}-6$. (Other occupations): Year: $\mathrm{t}(13)=1.19, P=0.256$. Mode of suicide: $\mathrm{t}(13)=-1.66, P=0.120$. Agriculture/other suicide mode (A_other), Agriculture/poison (A_poison), Other occupation/other suicide mode (O_other), Other occupation/poison (O_poison). (C) The median age was higher in other occupations relative to agriculture. Linear regression model. Occupation: $\mathrm{t}(42)=3.27,{ }^{*} P=0.002$.

descriptive reports and social analyses on farmer suicides driven by economic debt. $7,8,17,20$

Based on the official Indian census reports from 2008 to 2016, Punjab had 926 deaths by suicide in all 22 districts. ${ }^{11}$ In comparison, this study reported 652 deaths by suicide in only 7 of the 22 districts in Punjab (Figure 2, panel A). Hence, more than two folds of suicide events were undocumented in government reports. In addition, Sidhu et al. reported $773,{ }^{20}$ while this study reported 1061 deaths by suicide in the Punjabi district, Sangrur, from 2000-2008. This comparison suggests that the data collection in our study is more inclusive and exhaustive than previous reports.

Limitations for this study include the lack of data related to the individuals' gender, literacy levels, as well as their mental health during the data collection process. Nevertheless, previous social and descriptive analyses have downplayed the role of potential pre-existing psychological disorders in driving suicide among farmers in India. ${ }^{7}$ Further, measuring debt is complicated. In this study, the debt value was directly assessed using household surveys, which reflects the total size of the debt. However, other indicators like the assets sold, family size, and annual income could have provided more information about the relationship between debt and suicide. In addition, other social and familial factors could have contributed to suicide. ${ }^{20}$ 

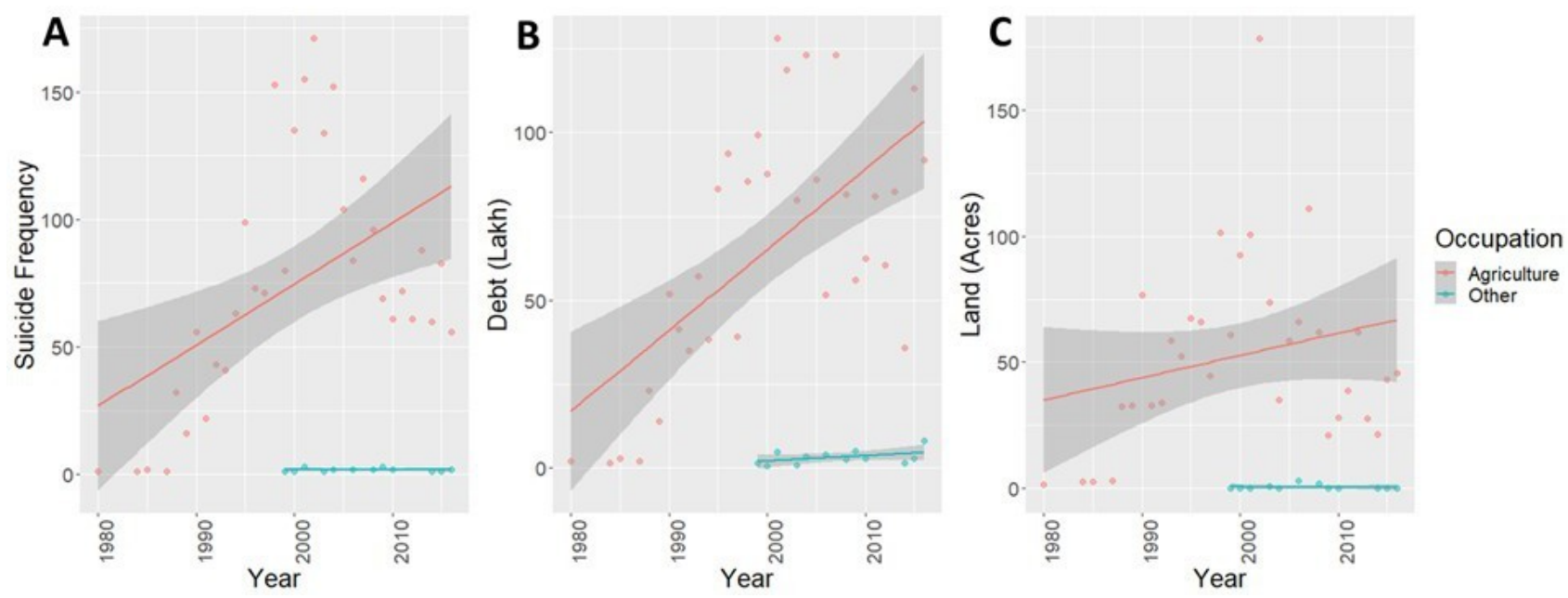

Figure 2. The variation of suicide frequency, debt, and land holding in all districts across the years.

(A) Suicide frequency increased among agricultural workers throughout the years. Linear regression model. (Agriculture). Year: $t(31)=3.24$, ${ }^{*} P=0.003$. (Other occupations). Year: $\mathrm{t}(10)=0.02, P=0.987$. (B) Debt (Lakh) increased among agricultural workers throughout the years. Linear regression model. (Agriculture). Year: $\mathrm{t}(31)=4.58 * P=7.17 e-5$. (Other occupations). Year: $\mathrm{t}(10)=1.61, P=0.140$. (C) The increase in land holding (Acres) across the years was not statistically significant. Linear regression model. (Agriculture). Year: $\mathrm{t}(31)=1.39, P=0.176$. (Other occupations). Year: $\mathrm{t}(10)=-0.35, P=0.736$.
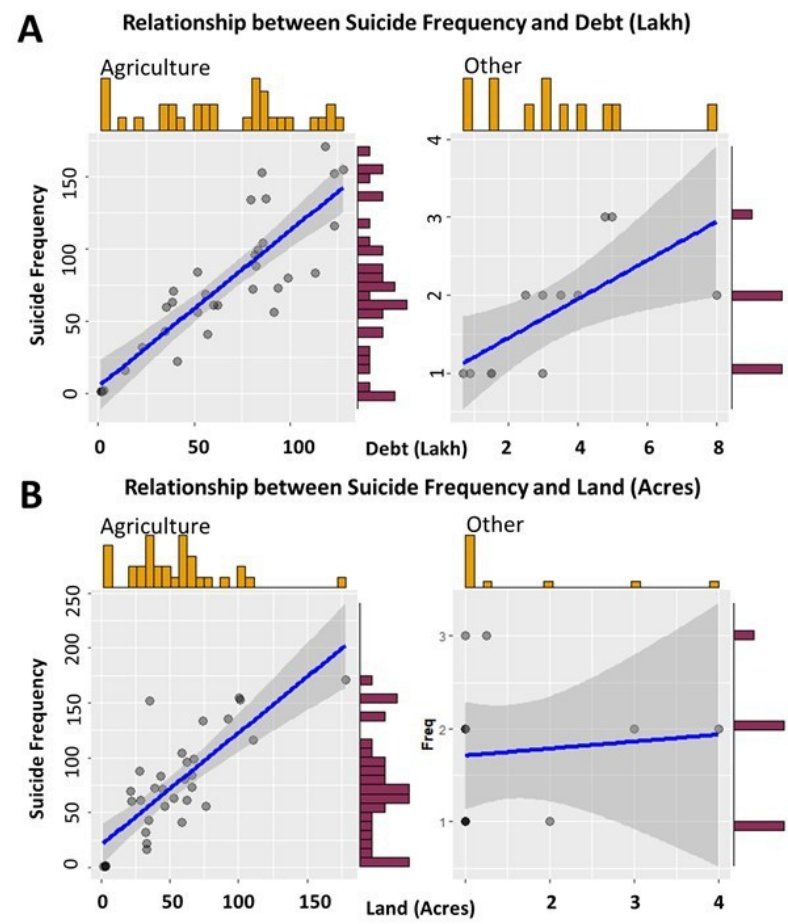

Figure 3. The relationship between suicide frequency, debt (Lakh), and land holding (acres).

(A) Debt (Lakh) influenced suicide frequency regardless of the occupation. Linear regression model (Agriculture). Debt: $\mathrm{t}(31)=9.36$, * $P=1.56 e-10$. (Other occupations). Debt: $\mathrm{t}(10)=2.97, * P=0.014$. There was a stronger correlation between suicide frequency and debt (Lakh) in agriculture (OR=2.94, 95\% CI [2.33-3.72]) relative to the other occupations (OR=1.28, 95\% CI [1.06-1.54]). (B) Land holding (Acres) influenced suicide frequency among agricultural workers. Linear regression model (Agriculture). Land holding: $\mathrm{t}(31)=7.08,{ }^{*} P=5.9 e-8$. (Other occupations). Land holding: $\mathrm{t}(10)=0.31, P=0.760$. This correlation was only evident in agriculture $(\mathrm{OR}=2.77,95 \% \mathrm{CI}[2.07-3.72])$ and not in other occupations (OR=1.08, 95\% CI [0.63-1.84]).

\section{CONCLUSIONS}

The data presented here identifies economically-driven trends in suicide in Punjab, India, and can herald problems that are likely to arise in other regions of the world where farmers suffer from increased economic insecurity. Further studies into the role of exploitive informal moneylenders, trade liberalization and multinational corporations, and the necessity of public investment into secondary and tertiary sectors of the economy are warranted to identify mechanisms to safeguard the socioeconomic human rights of farmers. 
Table 1. Summary of the median age (years) for the recorded suicide cases per year in Punjab, India

\begin{tabular}{|c|c|c|c|}
\hline Occupation & Year & Median age (years) & Average median age (years) \\
\hline \multirow[t]{33}{*}{ Agriculture } & 1980 & 25 & \multirow[t]{33}{*}{32.8} \\
\hline & 1984 & 42 & \\
\hline & 1985 & 36 & \\
\hline & 1987 & 45 & \\
\hline & 1988 & 32 & \\
\hline & 1989 & 30 & \\
\hline & 1990 & 34 & \\
\hline & 1991 & 35 & \\
\hline & 1992 & 28 & \\
\hline & 1993 & 30 & \\
\hline & 1994 & 30 & \\
\hline & 1995 & 30 & \\
\hline & 1996 & 26 & \\
\hline & 1997 & 30 & \\
\hline & 1998 & 32 & \\
\hline & 1999 & 30 & \\
\hline & 2000 & 30 & \\
\hline & 2001 & 31 & \\
\hline & 2002 & 30 & \\
\hline & 2003 & 30 & \\
\hline & 2004 & 30 & \\
\hline & 2005 & 32 & \\
\hline & 2006 & 30 & \\
\hline & 2007 & 32 & \\
\hline & 2008 & 33 & \\
\hline & 2009 & 35 & \\
\hline & 2010 & 35 & \\
\hline & 2011 & 33 & \\
\hline & 2012 & 35 & \\
\hline & 2013 & 35.5 & \\
\hline & 2014 & 36.5 & \\
\hline & 2015 & 38 & \\
\hline & 2016 & 40 & \\
\hline \multirow[t]{12}{*}{ Other occupations } & 1999 & 40 & \multirow[t]{12}{*}{39.3} \\
\hline & 2000 & 32 & \\
\hline & 2001 & 40 & \\
\hline & 2003 & 55 & \\
\hline & 2004 & 32.5 & \\
\hline & 2006 & 37 & \\
\hline & 2008 & 42.5 & \\
\hline & 2009 & 28 & \\
\hline & 2010 & 41 & \\
\hline & 2014 & 38 & \\
\hline & 2015 & 46 & \\
\hline & 2016 & 40 & \\
\hline
\end{tabular}




\section{ACKNOWLEDGEMENTS}

This study does not constitute human subjects research as all subjects are deceased. Institutional Review Board (IRB) approval was obtained from Weill Cornell Medicine to use protected health information (PHI) for descendants of this study for research purposes.

\section{DATA AVAILABILITY}

Data is available upon request from the corresponding author.

\section{FUNDING}

No funding was involved in the preparation of this manuscript.

\section{AUTHORSHIP CONTRIBUTIONS}

FT, MW, and EM cleaned and analyzed the data. FT made the figures. ISJ and his team collected the data. FT, SJ, JL,
GK wrote and reviewed the manuscript. GK supervised the study.

\section{COMPETING INTERESTS}

The authors completed the Unified Competing Interest form at www.icmje.org/coi_disclosure.pdf (available upon request from the corresponding author), and declare no conflicts of interest.

\section{CORRESPONDENCE TO:}

Gunisha Kaur, MD, MA

Weill Cornell Medicine

525 East 68th Street Box 124

New York, NY 10065

gus2004@med.cornell.edu

Submitted: March 10, 2021 BST, Accepted: March 30, 2021 BST

This is an open-access article distributed under the terms of the Creative Commons Attribution 4.0 International License (CCBY-4.0). View this license's legal deed at http://creativecommons.org/licenses/by/4.0 and legal code at http://creativecommons.org/licenses/by/4.0/legalcode for more information. 


\section{REFERENCES}

1. NIMH. Suicide. National Institute of Mental Health; 2020.

2. De Berardis D, Martinotti G, Di Giannantonio M. Editorial: Understanding the Complex Phenomenon of Suicide: From Research to Clinical Practice. Front Psychiatry. 2018;9:61. doi:10.3389/fpsyt.2018.00061

3. Peterson C, Stone D, Marsh S, et al. Suicide Rates by Major Occupational Group - 17 States, 2012 and 2015. MMWR Morb Mortal Wkly Rep.

2018;67:1253-1260. doi:10.15585/mmwr.mm6745a1e xternal

4. Ye J, He C, Liu J, Wang W, Chen S. Left-behind elderly: shouldering a disproportionate share of production and reproduction in supporting China's industrial development. The Journal of Peasant Studies. 2017;44(5):971-999. doi:10.1080/03066150.20 $\underline{16.1186651}$

5. Perceval M, Kõlves K, Reddy P, De Leo D. Farmer suicides: a qualitative study from Australia. Occupational Medicine. 2017;67(5):383-388. doi:10.10 93/occmed/kqx055

6. Carleton TA. Crop-damaging temperatures increase suicide rates in India. Proceedings of the National Academy of Sciences. 2017;114(33):8746-8751. doi:1 $\underline{0.1073 / p n a s .1701354114}$

7. Sathyanarayana Rao TS, Gowda MR, Ramachandran K, Andrade C. Prevention of farmer suicides: Greater need for state role than for a mental health professional's role. Indian J Psychiatry. 2017;59(1):3-5. doi:10.4103/psychiatry.IndianJPsychi atry_89_17

8. Vasavi AR. Suicides and the making of India's agrarian distress. South African Review of Sociology. 2009;40(1):94-108. doi:10.1080/21528586.2009.10425 102

9. Saaliq S. India's winter of discontent: Farmers rise up against Modi. Associated Press. 2020.

10. Pingali PL. Green Revolution: Impacts, limits, and the path ahead. Proceedings of the National Academy of Sciences. 2012;109(31):12302-12308. doi:10.1073/pna s.0912953109

11. Office of the Registrar General \& Census Commissioner India. Medical Certification of Cause of Death. Ministry of Home Affairs; 2020. https://censusi ndia.gov.in/2011-Common/mccd.html
12. Aggarwal S. Suicide in India. Br Med Bull. 2015;114(1):127-134. doi:10.1093/bmb/ldv018

13. Kaur L, Sharmaand P, Garg L. Causes and Cure of Farmer's Suicide. Indian Journal of Economics and Development. 2016;12(1a):305-310.

14. Behere PB, Bhise MC. Farmers' suicide: Across culture. Indian J Psychiatry. 2009;51(4):242-243. doi:1 0.4103/0019-5545.58286

15. Browning SR, Westneat SC, McKnight RH. Suicides among farmers in three southeastern states, 1990-1998. J Agric Saf Health. 2008;14(4):461-472. do $\mathrm{i}: 10.13031 / 2013.25282$

16. Kunde L, Kõlves K, Kelly B, Reddy P, De Leo D. Pathways to Suicide in Australian Farmers: A Life Chart Analysis. Int J Environ Res Public Health. 2017;14(4). doi:10.3390/ijerph14040352

17. Center for Human Rights and Global Justice. Every Thirty Minutes: Farmer Suicides, Human Rights, and the Agrarian Crisis in India.; 2011. https://chrgj.org/wp-co ntent/uploads/2016/09/Farmer-Suicides.pdf

18. Patel V, Ramasundarahettige C, Vijayakumar L, et al. Suicide mortality in India: a nationally representative survey. Lancet.

2012;379(9834):2343-2351. doi:10.1016/s0140-6736(1 2)60606-0

19. Piscopo KD. Suicidality and Death by Suicide Among Middle-Aged Adults in the United States.; 2017. https://www.samhsa.gov/data/sites/default/files/repo rt 3370/ShortReport-3370.html

20. Sidhu RS, Singh S, Bhullar AS. Farmers' Suicides in Punjab: A Census Survey of the Two Most Affected Districts. Economic and Political Weekly. 2011;46(26/ 27):131-137.

21. Chowdhury AN, Banerjee S, Brahma A, Weiss MG. Pesticide practices and suicide among farmers of the sundarban region in India. Food Nutr Bull. 2007;28(2 Suppl):S381-91. doi:10.1177/15648265070282s218

22. Bonvoisin T, Utyasheva L, Knipe D, Gunnell D, Eddleston M. Suicide by pesticide poisoning in India: a review of pesticide regulations and their impact on suicide trends. BMC Public Health. 2020;20(1):251. do $\mathrm{i}: 10.1186 / \mathrm{s} 12889-020-8339-\mathrm{z}$ 
23. Booth N, Briscoe M, Powell R. Suicide in the farming community: methods used and contact with health services. Occupational and Environmental Medicine. 2000;57(9):642-644. doi:10.1136/oem.57.9.6 $\underline{42}$ 